\title{
VIVÊNCIAS DE FAMILIARES NO PROCESSO DE NASCIMENTO E INTERNAÇÃO DE SEUS FILHOS EM UTI NEONATAL
}

\author{
Family life experience in the process of birth and hospitalization of a child in a neonatal \\ ICU
Vivencias de familiares en el proceso de nacimiento e internación de sus hijos en UCI neonatal

Kézia de Oliveira

Marly Veronez ${ }^{2}$

leda Harumi Higarashi ${ }^{3}$

Darci Aparecida Martins Corrêa ${ }^{4}$

\section{RESUMO}

A expectativa que envolve o nascimento de um filho está atrelada à ideia de levar um bebê saudável para casa. Contudo, tal desejo, acalentado ao longo de toda gestação, nem sempre se concretiza. Este estudo, de caráter qualitativo-descritivo, teve por objetivo conhecer a vivência de pais que tiveram seu bebê internado na Unidade de Terapia Intensiva Neonatal (UTIN) desde o nascimento. Participaram do estudo seis mães que tiveram seus filhos internados em um hospital de ensino e foram entrevistadas com o uso de um roteiro semiestruturado. Os dados foram analisados segundo o referencial de Bardin, originando a seguinte temática central: vivência dos pais no processo de hospitalização do filho em UTIN e três subtemáticas: vivenciando sentimentos de separação e abandono; experienciando o medo da perda; identificando dificuldades e encontrando fontes de apoio. 0 estudo evidenciou a importância de envolver a família no processo assistencial como fator precursor da qualidade da atenção humanizada.

Palavras-chave: Enfermagem. Unidades de terapia intensiva neonatal. Recém-nascido. Hospitalização. Família.

\begin{abstract}
The expectation that involves the birth of a child is linked to the idea of taking home a healthy baby. However, what was dreamt throughout the entire pregnancy is not always possible. This is a study of qualitative-descriptive character, with the purpose of getting to know the parents who had their babies in the Neonatal Intensive Care Unit (NICU) from the moment of birth. It took part in the study 6 mothers who had their children admitted in a university hospital. The subjects were interviewed through a semi-structured instrument. Data was analyzed according to Bardin's referential, originating the main theme: the parents' experience in the process of having a child in a NICU, and three sub-themes: living with feelings of separation and abandonment; experiencing the fear of loss; identifying difficulties and finding sources of support. The study evidenced the importance of involving the family in the assistance process, as a precursory factor of the quality of the humanized attention.
\end{abstract}

Keywords: Nursing. Neonatal Intensive Care Unit; Newborn. Hospitalization. Family.

\section{Resumen}

La expectativa que envuelve el nacimiento de un hijo está vinculada a la idea de llevar a un bebé sano para casa. Sin embargo, tal deseo, calentado a lo largo de toda gestación, ni siempre se concretiza. Estudio de carácter cualitativo-descriptivo, tuvo por objetivo conocer la vivencia de padres que tuvieron su bebé internado en la Unidad de Cuidados Intensivos Neonatal (UCIN) desde el nacimiento. Participaron del estudio, seis madres que tuvieron sus hijos internados en un hospital-escuela, y fueron entrevistadas utilizándose de un guión semiestructurado. Los datos fueron analizados según el referencial de Bardin, originando la siguiente temática central: vivencia de los padres en el proceso de hospitalización del hijo en UCIN. Emergieron tres subtemáticas: vivenciando sentimientos de separación y abandono; experimentando el miedo de la pérdida; identificando dificultades y encontrando fuentes de apoyo. El estudio evidenció la importancia de involucrar a la familia en el proceso asistencial como factor precursor de la calidad de la atención humanizada.

Palabras clave: Enfermería. Unidades de cuidados intensivos neonatales. Recién nacido. Hospitalización. Familia.

\footnotetext{
Enfermeira. Especialista em Saúde da Família e UTI Neonatal. Docente do Centro Universitário de Maringá (CESUMAR). Mestranda do Programa de Pósgraduação em Enfermagem (PSE) da Universidade Estadual de Maringá (UEM) - Maringá - PR. Brasil. keziamariscal@hotmail.com; ²Enfermeira. Especialista em Fisiologia Humana (UEM). Enfermeira da Unidade de Terapia Intensiva Neonatal do Hospital Universitário Regional de Maringá. Mestranda do Programa de Pós-graduação em Enfermagem (PSE) da Universidade Estadual de Maringá (UEM) - Maringá - PR. Brasil. marlyveronez@gmail.com; ${ }^{3}$ Enfermeira. Doutora em Educação. Docente do Departamento de Enfermagem (DEN) e Coordenadora Adjunta do PSE/UEM - Maringá - PR. Brasil. ieda1618@gmail.com; ${ }^{4}$ Enfermeira. Doutora em Enfermagem. Docente do Departamento de Enfermagem (DEN) da Universidade Estadual de Maringá (UEM) - Maringá - PR. Brasil. osculo@nobel.com.br
} 


\section{INTRODUÇÃO}

Desde as mais remotas civilizações, quando homem e mulher iniciaram a definição de seus papéis sociais, o processo de gestação e nascimento de um filho já representava para muitas famílias a concretização de um sonho acalentado. Faz parte desse sonho a expectativa por um filho saudável, capaz de perpetuar os valores e características peculiares de cada família, transformando-se, assim, em fonte inesgotável de esperança, orgulho e, principalmente, de realização de seus pais no contexto de suas atribuições sociais.

Para além das questões referentes a tais expectativas, a chegada de um filho representa também o ponto de origem de uma série de transformações no seio familiar, seja em razão da aquisição de novos papéis e responsabilidades pelos membros da família, seja pela angústia e apreensão de que algo possa afetar o curso planejado, especialmente quando ocorre um nascimento de um filho prematuro e/ou de risco.

Quando uma situação como esta se apresenta, os pais, não raramente, vivenciam a sensação de "perder o chão" e, repentinamente veem seus sonhos e sentimentos de alegria cederem lugar a uma realidade cercada por angústia, insegurança e medo.

Em meio a esse turbilhão de emoções, as famílias ainda se veem diante das possibilidades de terem seu bebê internado em uma Unidade de Terapia Intensiva neonatal (UTIN), consolidando, muitas vezes, o distanciamento do filho e a sensação de perda, conduzindo os pais a um sentimento de luto.

A expectativa de levar o bebê para casa é tida como um ideal acalentado pela família deste o início da gestação e sustentado quase que diariamente pelos pais até o nascimento de seu filho. Nesse sentido, a partir do momento em que recebem a notícia de que seu filho necessitará de atendimento especializado, em uma UTIN, os pais são surpreendidos por outros sentimentos além daqueles gerados pelo nascimento de um bebê de risco, tais como o desespero, a angústia e a insegurança quanto ao futuro que, repentinamente, se torna incer to e ameaçado pelo medo e pela culpa de deixar seu filho hospitalizado em uma UTIN e não levá-lo para casa.

As famílias, ao descreverem suas percepções e sentimentos acerca dos conceitos referentes à UTIN, definemnas como " $[. .$.$] um ambiente hostil e pouco acolhedor$ desencadeando sentimentos e reações desagradáveis como tristeza, ansiedade, angústia e principalmente medo" $1: 736$.

No intuito de transformar esse "quase" paradigma, alimentado pelo senso comum que associa o termo Unidade de Terapia Intensiva (UTI) à noção de dor e morte, é possível perceber que, nos últimos trinta anos, grandes mudanças vêm sendo implementadas nesses ambientes, acompanhando de certa forma uma tendência mundial. Deste modo, a incorporação de novas tecnologias, o ingresso crescente de diferentes categorias profissionais nesses serviços, a presença cada vez mais frequente dos pais em setores antes tão restritos e o cuidado de recém-nascidos (RNs) cada vez menores já fazem parte de uma realidade que exige posturas diferentes dos profissionais da equipe de saúde neonatal2.

Nessa perspectiva, a associação entre a oferta desses recursos altamente sofisticados e uma abordagem humanizada das famílias e pacientes que eventualmente necessitem utilizarse de tal suporte tecnológico em UTIN vem ocorrendo nas últimas décadas por meio de muitas iniciativas, dentre elas 0 Programa Nacional de Humanização da Assistência Hospitalar (PNHAH), lançado pelo Ministério da Saúde, o qual tem como objetivo estabelecer diretrizes para a implantação, desenvolvimento, sustentação e avaliação de iniciativas de humanização nos hospitais do SUS 3 .

Como parte dessas diretrizes, a assistência à família eà criança no processo saúde-doença inclui três abordagens interrelacionadas da equipe de saúde que podem variar conforme a perspectiva filosófica de cada instituição. Essas abordagens podem estar centradas na patologia, na criança, ou ainda na criança e em sua família, sendo esta última a que melhor parece atender os preceitos atuais da humanização e integralidade da atenção4.

Portanto, e em se tratando das realidades da atenção intensiva neonatal, desvelar as vivências dos pais nessas circunstâncias torna-se condição essencial para a busca de ferramentas e estratégias adequadas, pautadas em um planejamento dinâmico voltado ao atendimento das necessidades dessas famílias, com vistas à minimização do trauma que pode ser ocasionado pela experiência de hospitalização da criança desde o nascimento.

Nesse sentido, o presente estudo teve como objetivo conhecer a vivência de pais que tiveram seus filhos internados em UTIN desde o nascimento, de modo a evidenciar as principais fontes de apoio utilizadas por estes para o enfrentamento da situação.

\section{METODOLOGIA}

Optou-se pela realização de pesquisa descritiva, transversal, de caráter qualitativo. Esse método se aplica ao estudo das crenças, das opiniões e dos valores dos indivíduos, permitindo o conhecimento do significado das ações e das relações humanas 5 .

A busca das fontes para a construção da revisão de literatura foi realizada no período de março e abril de 2011, nas bases de dados: Literatura Internacional em Ciências da Saúde (MEDLINE), Literatura Latino-Americana e do Caribe em Ciências da Saúde (LILACS) e Scientific Eletronic Library Online (SciELO). Foram utilizados os seguintes descritores iniciais de busca: Enfermagem, recém-nascido, hospitalização, família e Unidade de Terapia Intensiva.

Fizeram parte do estudo seis pais de recém-nascidos (RNs) internados na UTIN do Hospital Universitário Regional de Maringá (HURM) por, no mínimo, 30 dias. Esse período 
mínimo foi considerado como critério de inclusão, considerando a experiência profissional das pesquisadoras e a constatação da frequência com que RNs atingem tal permanência na realidade investigada. Essa é, em geral, justificada pela condição de imaturidade desses bebês e decorrente da necessidade de suporte tecnológico específico ao nascer. Ademais, o prolongamento desse período de permanência permite um contato maior entre a família e a equipe de saúde, possibilitando 0 acompanhamento de todo o processo de enfrentamento e adaptações por que passa a família nessa situação.

A coleta dos dados ocorreu no período de maio a junho de 2011, por meio da implementação de entrevistas a partir de roteiro semiestruturado, dividido em duas partes, sendo uma destinada à caracterização sociodemográfica dos participantes e outra destinada à abordagem da temática central do estudo a partir da seguinte questão norteadora: Descreva para mim como está sendo enfrentar a hospitalização de seu filho na UTINeonatal.

Ocorreram, no período, oito internações de RNs com permanência igual ou superior a 30 dias. Todas as entrevistas foram realizadas exclusivamente com as mães dos bebês internados, posto que estas representassem o membro familiar presente em todas as abordagens do estudo. Da população inicialmente pretendida, contudo, foram excluídas duas mães, uma por problemas técnicos no registro/gravação da entrevista e a outra por impossibilidade de agendamento de horários. Deste processo, portanto, resultou uma amostra formada por seis mães.

As entrevistas foram registradas por meio de utilização de um gravador digital, com posterior transcrição. Os dados referentes à caracterização foram organizados e apresentados em tabelas, e os que tratam da temática central do estudo foram analisados qualitativamente. Para tanto, foram submetidos à análise temática de conteúdo e organizados a partir da identificação dos núcleos de sentidos presentes nas falas. A técnica de análise de conteúdo categorial temática é definida como um "conjunto de técnicas de análise das comunicações que utiliza procedimentos sistemáticos e objetivos de descrição do conteúdo das mensagens", cuja técnica proporciona ao pesquisador conhecer as palavras e suas significações por meio da implementação de três fases: préanálise, exploração do material e inferência e interpretação ${ }^{6}$.

De modo a preservar a identidade das participantes, sem perda do enfoque individualizado dos relatos, optou-se por identificar as mães por nomes de flores, que simbolizam, de certa forma, todo o paradoxo da beleza, força e fragilidade da condição/natureza materna retratada neste estudo.

0 projeto de pesquisa foi apreciado e aprovado pelo Comitê Permanente de Ética em Pesquisa Envolvendo Seres Humanos da Universidade Estadual de Maringá (UEM), conforme Parecer $n^{\circ} 302 / 2011$. As entrevistas ocorreram em consonância com todos os preceitos éticos estabelecidos pela Resolução 196/96 do Conselho Nacional de Saúde/ Ministério da Saúde. Foram incluídas no estudo somente as participantes que, após a devida instrução e esclarecimento sobre o estudo, assinaram o Termo de Consentimento Livre e Esclarecido em duas vias de igual teor.

\section{RESULTADOS E DISCUSSÃO}

O local de realização do estudo foi a UTIN de um hospital de ensino, localizado no noroeste do Paraná. A unidade em questão conta com uma média de 18 internamentos ao mês, abrangendo, em sua maioria, RNs acometidos por alguma patologia ou complicações relativas ao nascimento, além de prematuros (com menos de 37 semanas de gestação). 0 período de internação também tem características variadas, estendendo-se de poucos dias até meses de permanência hospitalar.

$\mathrm{Na}$ amostra analisada, a idade das genitoras variou de 16 a 35 anos, sendo que quatro das mães apresentavam idade igual ou inferior a 21 anos. Quanto à ocupação, apenas uma das participantes tinha emprego fora do lar, como doméstica. 0 nível de escolaridade de cinco das seis mães era o ensino médio completo, e, em termos da situação conjugal, apenas uma referiu ser solteira, sendo as demais casadas em regime de união estável. A renda familiar referida variou de 1 a 3,6 salários mínimos, e a religião predominante foi a católica. Os dados de caracterização da amostra são apresentados no Quadro 1.

Quadro 1 - Caracterização das mães de RNs internados na UTIN de hospital de ensino do noroeste do Paraná no

período de maio /junho de 2011. Maringá - PR

\begin{tabular}{|l|l|l|l|l|l|l|l|l|}
\hline Mães & Idade & Estado Civil & Escolaridade & $\begin{array}{c}\text { Filhos } \\
\text { Vivos }\end{array}$ & $\begin{array}{c}\text { Tipo de } \\
\text { Parto }\end{array}$ & Profissão & $\begin{array}{c}\text { Salário } \\
\text { mínimo (\%) }\end{array}$ & Religião \\
\hline Azaleia & 31 & Casada & $\begin{array}{l}\text { Médio } \\
\text { Completo }\end{array}$ & 2 & Cesáreo & Doméstica & 1.1 & Católica \\
\hline Camélia & 21 & Amasiada & $\begin{array}{l}\text { Ensino } \\
\text { Fundamental }\end{array}$ & 0 & Cesáreo & Do Lar & 3,6 & Evangélica \\
\hline Dália & 19 & Amasiada & $\begin{array}{l}\text { Médio } \\
\text { Completo }\end{array}$ & 1 & Cesáreo & Do Lar & 1,0 & Católica \\
\hline Flor-de-lis & 18 & Solteira & $\begin{array}{l}\text { Médio } \\
\text { Completo }\end{array}$ & 2 & Cesáreo & Do Lar & 1,0 & Católica \\
\hline Hortência & 35 & Casada & $\begin{array}{l}\text { Médio } \\
\text { Completo }\end{array}$ & 1 & Normal & Do Lar & 3,1 & Católica \\
\hline Girassol & 16 & Amasiada & $\begin{array}{l}\text { Médio } \\
\text { Completo }\end{array}$ & 1 & Cesáreo & Do Lar & 2,2 & Católica \\
\hline
\end{tabular}


Com relação à caracterização dos RNs, observou-se que a totalidade das internações logo após o nascimento foi motivada pela prematuridade ( $100 \%$ dos casos). 0 baixo peso também foi um achado presente na totalidade dos RNs, cujos pesos variaram entre $1.060 \mathrm{e} 1.500 \mathrm{~g}$. Os RNs prematuros são definidos pela Organização Mundial da Saúde como aqueles nascidos com idade inferior a 37 semanas de gestação e peso fetal menor que $2.500 \mathrm{~g}^{7}$. A condição de prematuridade associada ao baixo peso extremo justificam, de certa forma, 0 longo período de internação que sucedeu ao nascimento dessas crianças, e que chegou, em um dos casos, a 67 dias na ocasião da entrevista.

No que tange às complicações iniciais da internação, é possível verificar no Quadro 2 que o tipo de problema mais encontrado em todos os casos foi relacionado ao aparelho respiratório. É sabido que os RNs prematuros, principalmente os nascidos com idade inferior a 32 semanas, estão propensos a esse tipo de complicação devido à imaturidade pulmonar e suscetibilidade a infecções decorrentes do imaturo sistema imunológico 8 .

Quadro 2. Caracterização dos RNs internados na UTIN no período de maio/junho de 2011. Maringá - PR

\begin{tabular}{|l|l|l|l|l|}
\hline RN & $\begin{array}{l}\text { Idade Gest. } \\
\text { (Semanas) }\end{array}$ & Peso de Internação & $\begin{array}{l}\text { Condiçōes de Saúde } \\
\text { Inicial }\end{array}$ & Dias de internação \\
\hline Azaleia & $31 \mathrm{se} 3$ dias & $1.330 \mathrm{~g}$ & Prob. Resp. & 30 dias \\
\hline Camélia & $31 \mathrm{se} 2$ dias & $1.210 \mathrm{~g}$ & Prob. Resp. & 67 dias \\
\hline Dália & $27 \mathrm{se} 6$ dias & $1.060 \mathrm{~g}$ & Prob. Resp. & 55 dias \\
\hline Flor-de-lis & $30 \mathrm{~s}$ & $1.135 \mathrm{~g}$ & Prob. Resp. & 45 dias \\
\hline Hortência & $34 \mathrm{~s}$ & $1.500 \mathrm{~g}$ & Prob. Resp. & 35 dias \\
\hline Girassol & $33 \mathrm{~s}$ & $1.285 \mathrm{~g}$ & Prob. Resp. & 43 dias \\
\hline
\end{tabular}

Legenda: Prob. Resp.= Problemas respiratórios (cansaço, infecções pulmonares). Idade Gest. $=$ semanas.

Após a caracterização dos sujeitos de estudo, foi iniciada a abordagem da temática central do estudo, qual seja, a vivência dos pais no processo de hospitalização do filho em UTI Neonatal. A análise de conteúdo dos discursos emanados dessa abordagem possibilitou o delineamento de três eixos temáticos, com seus respectivos subtemas: Vivenciando sentimentos de separação e abandono; Experienciando o medo da perda; Identificando dificuldades e encontrando fontes de apoio.

\section{Vivenciando sentimentos de separação e abandono}

A alta materna não é vista pela mãe apenas como um momento de alívio pela saída do hospital, uma vez que representa também uma situação de dor pela separação do filho RN que ainda precisa permanecer internado. A realização do desejo acalentado ao longo de toda gestação, de voltar para a casa com o filho idealizado e saudável, é novamente adiado.

A separação do filho, por ter que deixá-lo na UTI, em um o cenário cheio de aparatos tecnológicos contribui para aumentar o desespero da família durante os dias de hospitalização, pois gera sentimentos de tristeza e medo ${ }^{9}$. As mães participantes deste estudo, e que tiveram que deixar seus filhos internados na UTIN, relataram que, ao chegarem em casa, o primeiro sentimento vivenciado foi a sensação de abandono dos bebês. Mesclados a esse emergiram também sentimentos de fracasso como mães, conforme pode ser evidenciado nas falas a seguir:

[...] Hum! Na hora que eu entrei na ambulância foi muito triste, daí eu vi que ela tinha que ficar mesmo né, tinha que melhorar para levar ela embora, ia ser bom para saúde dela [...] (Azaleia).

[...] deixar ele, chega doer meu coração, fui embora chorando, eu vim todos os dias ver ele [...] sinto muito a falta dele (Camélia).

[...] foi constrangedor, eu achei um momento muito difícil, por que você espera sair com a criança [...] (Girassol).

Nessas falas, observa-se que as mães exprimem uma sensação de frustração ante a impossibilidade de viver a expectativa cultivada ao longo de toda a gravidez, já que o desfecho esperado desse processo é o nascimento de um filho sadio que possa ser imediatamente integrado ao seio familiar. No entanto, nos casos em que isto é inviabilizado, seja pelo nascimento prematuro do bebê, seja em decorrência de alguma intercorrência que obrigue uma permanência maior do RN no hospital, são comuns as reações de tristeza e desamparo diante de tal situação $0^{10}$.

0 processo de hospitalização acarreta repercussões e impactos variados sobre o paciente e sua família, afetando, no caso da internação neonatal, especialmente a mãe do $\mathrm{RN}^{10}$. Isso pode ser atribuído quando se reconhece nessa situação a existência de uma unidade inseparável, representada pelo binômio mãe e filho, em que ambos compartilham e são afetados pelas experiências vivenciadas ao longo de todo o processo de gestação, parto e pós-parto. Resta à mãe, como parte consciente desse binômio, a missão de experimentar todas as angústias 
que permeiam esse momento, manifestas na forma de sentimentos por vezes antagônicos, como o alívio de receber a alta e poder retornar para junto de sua família, intercalado com a apreensão acerca do futuro de seu filho que permanece internado.

Ai, é muito ruim [...] por uma parte fiquei feliz, por que eu não aguentava mais o hospital, é horrivel né? Mais eu fiquei muito sentida, porque ela tinha que ficar [...] fiquei com medo de ela piorar e eu não estar aqui do lado dela (Hortência).

\section{Experienciando o medo da perda}

Essa temática categorial agrupa os depoimentos das mães que expressaram o medo de perder seu filho. Invariavelmente, esse medo era resultante do conceito que elas traziam acerca do que vem a ser uma Unidade de Terapia Intensiva (UTI). Fica evidente nas falas das mães participantes o estigma atribuído a esse tipo de serviço, visto comumente como um ambiente para o qual vão as pessoas que se encontram em estado muito grave, ou que podem vir a morrer a qualquer momento.

Tal observação corrobora os achados de um estudo ${ }^{1}$ no qual os pais afirmaram que ter um filho prematuro em uma UTIN representava para eles a sensação de insegurança, decorrente da condição de fragilidade do RN, bem como a possibilidade de este não sobreviver.

Assim, percebe-se nos relatos das mães entrevistadas que o medo da perda iminente e do desconhecido pode transformar um momento que poderia ser de alegria pelo nascimento de um filho em um episódio cercado de angústias, dúvidas e incertezas sobre o futuro próximo.

\section{[...] chorava todo dia [...] porque eu tinha medo de acontecer a mesma coisa que aconteceu com o outro [...] de ela morrer (Flor-de-lis).}

Esse receio é ainda mais intenso, no caso de Flor-delis, uma vez que esta já vivenciara a experiência dolorosa de perder um filho em situação semelhante.

Cada novo progresso ou complicação representa, para essas mães, sobressaltos nesse processo de enfrentamento, ora aumentando o receio da perda, ora acendendo uma luz de esperança referente ao destino incerto de seus filhos.

[...] depois que eu ganhei ele, eu achei que ia embora comigo né, mais ele teve que ficar aqui e operar. Eu tive medo de ele passar por tudo isso, porque ele operou do sopro do coração [...] eu achei que ele ia embora, mas não, vai fazer três meses que está aqui [...] (Camélia).
As dificuldades foram os exames [...] cada exame para mim foi uma agonia para saber a resposta [...] para mim foi uma luta, no sentido emocional. Também ter descoberto que ela tem um problema no cérebro, para mim foi a parte mais difícil... eu tinha medo que ela morresse [...] Tenho medo que ela possa crescer com algumas dificuldades, que ainda não sabemos qual é (Girassol).

Essa rotina da UTIN, caracterizada especialmente pelas transformações bruscas do estado geral dos RNs, pela necessidade de implementação de procedimentos inesperados, alimenta a sensação de insegurança dos pais que acompanham esse processo. Isso, aliado muitas vezes à falta de conhecimentos mais consistentes acerca da condição ou doença de seu filho, torna a experiência desses pais deveras angustiante.

Nesse sentido, e ainda que cada notícia ou informação nova desperte ansiedade nos pais do RN internado, é essencial a manutenção de um canal permanente de comunicação entre a equipe de saúde e os pais do bebê hospitalizado.

A internação em uma UTIN costuma provocar muito medo na família, não apenas pelo ambiente físico desconhecido e pela gravidade dos casos que recebem assistência nesse ambiente, mas também porque a família perde o contato com o filho, que passa, de certo modo, a "pertencer" aos profissionais de saúde ${ }^{11}$.

Esses sentimentos de medo e de perda, em suas diversas magnitudes, não podem ser ignorados, mas sim encarados e trabalhados mediante apoio e diálogo constante da equipe junto à família. É justamente nesse processo de enfrentamento e adaptações cotidianas que se torna possível a elaboração de estratégias que capacitem os pais a lidarem com os desafios diários dessa experiência, que podem redundar na recuperação completa de seus bebês ou na perda irreparável destes para a morte.

\section{Identificando dificuldades e encontrando fontes de apoio}

Para além do processo de enfrentamento e elaboração interna que as mães se veem obrigadas a fazer diante da situação de doença e internação de seus bebês, existem outras dificuldades objetivas, de ordem operacional e material, que interferem profundamente no sucesso desse enfrentamento.

Se eu tivesse mesmo um carro, eu viria todos os dias [...] a ambulância, demora muito [...] meu marido disse para eu vir de circular, mas daí eu disse? E o dinheiro? (Camélia).

Assim, a falta de recursos financeiros, bem como os transtornos para o deslocamento dos domicílios ao hospital, entre outros, foram apontados pelas mães como grandes 
dificultadores para o acompanhamento mais continuado do bebê internado e, por conseguinte, para a conquista mais rápida de uma condição de equilíbrio familiar.

0 acúmulo e a repercussão das demandas geradas pela hospitalização obrigam as famílias a alterarem substancialmente suas rotinas, criando outras prioridades. Pode-se dizer que, quando um filho adoece, por mais estruturada que seja a família, todos adoecem juntos ${ }^{12}$. Nos casos em que a família já conviva com dificuldades financeiras ou de estruturação, a hospitalização do ente querido só vem exacerbar tal conjuntura, gerando uma dose extra de sobrecarga, desconfor to e cansaço, sobretudo para as mães.

Quanto melhor a parte financeira melhor a situação [...] eu acho que se eu tivesse condição de ter uma pessoa para me ajudar, porque a minha mãe me ajuda, mas ela tem a casa dela tem as coisas dela, eu gostaria de poder pagar uma pessoa que ficasse todo dia comigo. Isso pra mim ajudaria muito, para eu ter mais tempo com os dois né... eu acho que dai eu daria mais atenção, principalmente a Sofia que precisa mais atenção (Girassol).

[...] Todos os dias a ambulância vem, sai de lá cinco e meia da manhã, aí só vai embora às três e meia da tarde [...] tem de levantar cedo, mas isso eu já estou me acostumando [...] (Azaleia).

Na busca de estratégias que permitam a superação de tais obstáculos, visando à busca de reestruturação desse núcleo familiar, o papel das fontes de apoio assume condição primordial. Nesse sentido, quando as mães participantes foram questionadas acerca das fontes de apoio acionadas por elas no processo de enfrentamento da internação em UTIN, foram apontados de forma mais importante os seguintes segmentos: equipe de saúde, família e religiosidade.

\section{Equipe de saúde}

A interação e o apoio da equipe de saúde foram indicados pelas mães como fatores fundamentais para 0 enfrentamento da experiência de hospitalização de seus filhos RNs enquanto aspecto facilitador do processo.

Nesse âmbito, as mães entrevistadas, em quase sua totalidade, relataram ter recebido assistência acolhedora tanto nos momentos que antecederam o nascimento de seus filhos, quanto ao longo de toda a internação. Essa assistência se deu na forma de orientações recebidas nesses períodos, bem como na possibilidade do acompanhamento especializado, capaz de suprir as demandas assistenciais do binômio, o que, por si só, contribuía para a redução da ansiedade e promoção de certa sensação de amparo e conforto das mães.
Nossa, foi muito difícil [...] mais daí eu pensei bem, que aqui ele ia ser mais cuidado, eles (enfermeiros), têm bastante cuidado com ele [...] (Dália).

Durante o processo de internação de um bebê de risco, não cabe somente à equipe de enfermagem a responsabilidade de construir uma comunicação efetiva com a família desse bebê, mas à equipe multiprofissional como um todo.

0 apoio dos profissionais de saúde no sentido de deixar os pais participarem do processo, e assim inseri-los no contexto do cuidado, é fundamental. Para que isso se viabilize, o diálogo é descrito como um momento especial, em que as famílias são informadas sobre o estado de saúde do filho e, deste modo, passam a se sentir devidamente valorizadas e inseridas no cotidiano de vida e atenção ao RN internado:

[...] Ah tem hora que a gente conversa com as enfermeiras e tem hora com os médicos; eles tão sempre conversando comigo e explicando que é melhor ela ficar aqui para o bem dela [...] então né eu aceitei numa boa (Camélia).

[...] As meninas da UTI que conversam bastante comigo [...] os médicos [...] a psicóloga (Flor-delis).

A equipe de enfermagem não deve se basear somente em suas habilidades técnicas, como contribuição para a recuperação do RN, mais sim assistir a família em suas dúvidas, oferecer apoio às suas iniciativas e favorecer o constante estímulo no desenvolvimento dos seus cuidados, valorizando os contextos físicos, socioeconômicos, culturais e espirituais ${ }^{13}$.

\section{Família}

A família aparece como outra fonte de apoio essencial, participando de forma ativa desse processo. A participação da família nuclear (pai, mãe e irmãos) e extensa (avós, tios e primos) nesse momento de fragilidade, e 0 apoio daqueles em quem se confia, tenham estes laços sanguíneos ou não (amigos, vizinhos), constituem um valioso suporte emocional ${ }^{14}$ nessa fase de vida permeada pela insegurança em relação à saúde do filho doente. Desta forma, o período de hospitalização permite aos pais identificar aqueles sujeitos que, dentro de seu grupo de relações, se destacam como mais significativos e capazes de contribuir, direta ou indiretamente, para o cuidado da criança, inclusive quando esta estiver no domicíi ${ }^{14}$.

Na perspectiva das mães acompanhantes, como as deste estudo, o marido ou companheiro, quando participante do processo de parturição, e envolvido emocionalmente com o bem-estar da mulher e do filho, representa um apoio 
fundamental para o cuidado do binômio. Assim, via de regra, o pai costuma ser a primeira pessoa da família a ter contato com o bebê na UTIN, cabendo a ele a responsabilidade pelas interações iniciais com a equipe de saúde, assumindo, além de suas tarefas profissionais, as incumbências domésticas durante esse período".

Meu marido, os meus vizinhos, todo mundo apoiando [...], dando aquela força [...] para não entrar em depressão, porque até agora eu estou me dando bem, pois tenho a ajuda deles todos (Azaleia).

Para aquelas mães que não podem contar com o apoio de um marido ou companheiro, como foi ocaso de duas das entrevistadas, tal sobrecarga assume a característica de uma jornada solitária, um suceder de medos e angústias sem ter com quem compartilhar:

Quem me apoiou foi minha mãe, as meninas da UTI que conversaram bastante comigo [...] mais foi a minha mãe, mas... Ah! Se eu tivesse um apoio do marido, era melhor nél [...] (Flor-de-lis)

\section{Religiosidade}

As crenças religiosas são mediadoras no processo saúde-doença na medida em que permitem o desenvolvimento de esquemas cognitivos que podem ampliar os recursos pessoais de enfrentamento, promovendo a sensação de incremento do controle e da autoestima, favorecendo a atribuição de significado aos eventos estressores ${ }^{15}$.

A espiritualidade, por sua vez, independente da crença ou prática religiosa de cada ser humano e surge como um fator marcante na experiência de familiares que se encontram com algum ente querido hospitalizado. No presente estudo, foi possível evidenciar a presença da espiritualidade no dia-a-dia da internação e no discurso das mães/familiares dos RNs. A fé em Deus, expressa nos depoimentos das mães, apresenta-se associada à ideia de esperança, confor to e alívio para o enfrentamento de todo esse processo.

Nos relatos das mães, a seguir, a fé é referenciada como suporte para o enfrentamento da angústia decorrente da internação de seu filho, enquanto Deus é sempre associado ao sentimento de força, segurança e conforto para a superação da situação de sofrimento e provação:

Quem está ajudando mais é Deus, me dando força pra mim aguentar tudo isso [...] todos os dias eu dobro o meu joelho eu agradeço a Deus que eu tenho ele. Deus está curando meu filho, é ele quem está me dando força [...] (Camélia).
A religiosidade é uma das estratégias para o desafio de enfrentamento da doença, permitindo à mãe utilizar-se de recursos e conceitos pautados em suas crenças para elaborar, compreender e lidar com a situaçãa $0^{16}$. Ao profissional de saúde cabe, portanto, respeitar e oferecer suporte à expressão dessa religiosidade, permitindo, sempre que possível, que a família estabeleça conexões com sua dimensão espiritual, no sentido de melhor enfrentar os percalços de tal experiência ${ }^{17}$.

\section{CONSIDERAÇÕES FINAIS}

A internação é sempre um momento difícil em qualquer situação, quando se trata de RNs prematuros esse fator tem uma conotação ainda maior. Embora o estudo retrate que os pais em sua maioria já tinham conhecimento da possibilidade de internação do filho, o choque do diagnóstico e a notícia e perspectiva do internamento em UTIN foram relatados como um episódio de suas vidas permeado de muitos sentimentos dolorosos.

0 ambiente da UTIN é considerado pela maioria das pessoas como um ambiente frio, asséptico e dificultador do processo de interação do binômio mãefilho. Entre as reações diante da notícia de necessidade de internação de seus bebês na UTIN, as mães destacaram, fundamentalmente, o medo da separação de seus filhos.

0 apoio adequado a essas mães, advindos de fontes diferenciadas como as descritas no presente estudo, aparece como fator fundamental à superação do trauma da hospitalização precoce e da separação do binômio em um momento tão crucial à formação do vínculo afetivo.

Deste modo, uma abordagem humanizada, que considere e respeite as características tão peculiares dessa clientela e situação, parece constituir-se no primeiro passo para que essas famílias consigam lidar adequadamente com a internação de seus filhos na UTIN, transformando esse desafio em uma oportunidade de aprendizagem e desenvolvimento pessoal.

Há que se reconhecer, assim, o papel essencial das redes de apoio a essas famílias e a importância de valorização de cada um desses elementos (família, equipe e religiosidade) para o sucesso e otimização do processo de enfrentamento familiar.

Nesse sentido, e ainda que se reconheça o potencial traumático desse evento nas vidas do RNs e de suas famílias, deve-se valorizar o poder da superação de que são dotados todos os seres humanos, transmutando sentimentos iniciais de constrangimento, angústia, tristeza e dor em espaços para o florescimento de novas expectativas e esperanças de convivência futura com o filho ${ }^{18}$.

Espera-se, assim, que este estudo oportunize reflexões que conduzam a um novo olhar profissional, centrado nas fragilidades e potencialidades específicas de cada clientela, 
de modo a construir fazeres individualizados que devolvam a cada paciente e família o poder para a superação das dificuldades.

\section{REFERÊNCIAS}

1.Carvalho JL, Araújo ACPF, Costa ICC, Brito RS,Souza NL. Representação social de pais sobre o filho prematuro na Unidade de Terapia Intensiva Neonatal. Rev. bras. enferm. 2009 set/out; 62(5): 734-38.

2.Costa R, Padilha MI. 0 hospital infantil como marco no atendimento ao recém-nascido de risco em Santa Catarina (1987-2009). Texto \& contexto enferm. 2010 jul/set; 19(3): 469-78.

3. Ministério da Saúde (BR), Secretaria de Assistência a Saúde. Programa Nacional de Humanização da Assistência Hospitalar. Brasília(DF): Ministério da Saúde, Secretaria de Assistência à Saúde. (Serie C. Projetos, Programas e Relatórios, n. 20; 2001).

4. Pettengil MAM, Ribeiro CAR, Borba RIH. O cuidado centrado na criança a na sua família: uma perspectiva para a atuação do enfermeiro pediatra. In:__. Enfermagem Pediátrica: a criança, o adolescente e sua família no hospital. Barueri (SP): Manole; 2008.

5. Minayo MCS. 0 desafio do conhecimento: pesquisa qualitativa em saúde. $12^{a}$ ed. São Paulo: Hucitec; 2010.

6. Bardin L. Análise de conteúdo. Tradução de Luis Antero Reto e Augusto Pinheiro. São Paulo (SP). Ed 70; 2010.

7. Ministério da Saúde (BR), Secretaria de Atenção à Saúde. Programa de Ações Programáticas e Estratégicas. Atenção a Saúde do recém-nascido: guia para os profissionais de saúde. Brasília(DF): Ministério da Saúde, Secretaria de Atenção a Saúde, Departamento de Ações Programáticas e Estratégicas; 2011

8. Tamez RN, Silva MJP. Alta hospitalar. In: Enfermagem na Unidade de Terapia Intensiva Neonatal: Assistência ao recém-nascido de alto risco. $4^{a}$ ed. Rio de Janeiro: Guanabara Koogan; 2009.

9. Costa SAF, Santos MJA, Villas Boas ASC. Compreendendo a vivência da familia com a internação do filho recém-nascido prematuro na UTI neonatal. Nursing (São Paulo). 2007 dez; 115(10): 560-4.

10. Davim RMB, Enders BC, Dantas JC, Silva RAR, Nóbrega EJPB. Método mãe-canguru: vivência de mães no alojamento conjunto. Rev. RENE; 2009 jan/mar. 10(1): 37-44.

11. Silva PSCL,Valença NC,Germano MR. Percepções dos profissionais de enfermagem intensiva frente a morte do recém-nascido. Rev. bras. enferm. $2010 \mathrm{mar} / \mathrm{abr} ;$ 63(2): 238-42.

12. Quintana AM, Arpini DM; Pereira CRR; Santos MS. A vivência hospitalar no olhar da criança internada. Ciênc. cuid. saúde. 2007 out/dez; 6(4): 414-23.
13. Souza TV, Oliveira ICS. Interação familiar/acompanhante e equipe de enfermagem no cuidado à criança hospitalizada: perspectivas para a enfermagem pediátrica. Esc. Anna Nery. 2010 jul/set; 14(3): 551-9.

14. Sousa JC, Silva LMS, Guimarães TA. Preparo para alta hospitalar do recém-nascido de risco de uma Unidade de tratamento intensivo neonatal: uma visão da família. Rev. Enferm. UFPE on line. 2008 abr/jun; [citado 2011 abr 27]; 2(2): 146-54. Disponível em: <http:// www.pediatriasaopaulo.usp.br/upload/pdf/1268.pdf>.

15. Bousso RS, Serafim TS, Misko MD. Histórias de vida de familiares de crianças com doenças graves: relação entre religião, doença e morte. Rev. Latino-Am. Enfermagem. 2010 mar/abr; 18(2): 156-62.

16. Paiva GJ. Religião, enfrentamento e cura: perspectivas psicológicas. Estud. psicol. 2007 jan/mar; 24(1): 99-104.

17. Souza, JR, Maftum MA, Bais DDH. 0 cuidado de enfermagem em face do reconhecimento da crença e/ ou religião do paciente: percepções de estudantes de graduação. Online braz. j. nurs. (Online). 2008; [citado 2011 abr 18]; 7(2): [aprox. 5 telas]. Disponível em: <http:// www.objnursing.uff.br/index.php/nursing/article/view/j.16764285.2008.1525>

18. Cruz ARM, Oliveira MMC, Cardoso MVLML, Lúcio IML. Sentimentos e expectativas da mãe com filho prematuro em ventilação mecânica. Rev. eletrônica enferm. [Internet]. 2010 mar; [citado 2011 mar 24]; 12(1): 133-9. Disponível em: < http://www.fen.ufg.br/revista/v12/n1/ v12n1a16.htm>. 